\title{
Contribution of structural order-disorder to the green photoluminescence of $\mathrm{PbWO}_{4}$
}

\author{
M. Anicete-Santos, ${ }^{1,2, *}$ E. Orhan, ${ }^{3}$ M. A. M. A. de Maurera, ${ }^{4}$ L. G. P. Simões, ${ }^{1}$ A. G. Souza, ${ }^{4}$ P. S. Pizani,,${ }^{5}$ E. R. Leite, ${ }^{1}$ \\ J. A. Varela, ${ }^{6}$ Juan Andrés, ${ }^{2}$ A. Beltrán, ${ }^{2}$ and E. Longo ${ }^{6}$ \\ ${ }^{1}$ LIEC, Department of Chemistry, Federal University of São Carlos (UFSCAR), P.O. Box 676, 13565-905, São Carlos, São Paulo, Brazil \\ ${ }^{2}$ Departament de Ciències Experimentals, Universitat Jaume I, P.O. Box 224, 12080, Castelló, Spain \\ ${ }^{3}$ Science des Procédés Céramiques et de Traitements de Surface, UMR CNRS 6638, Faculté des Sciences et Techniques, \\ Université de Limoges, 87060 Limoges Cedex, France \\ ${ }^{4}$ Department of Chemistry, Federal University of Paraíba, 58059-900, João Pessoa, Paraíba, Brazil \\ ${ }^{5}$ Department of Physics, UFSCAR, P.O. Box 676, 13565-905, São Carlos, São Paulo, Brazil \\ ${ }^{6}$ LIEC, Institute of Chemistry, UNESP, P.O. Box 355, 14801-907, Araraquara, São Paulo, Brazil \\ (Received 25 September 2006; revised manuscript received 15 January 2007; published 11 April 2007)
}

\begin{abstract}
An intense and broad visible photoluminescence (PL) band was observed at room temperature in structurally disordered $\mathrm{PbWO}_{4}$ thin films. The scheelite lead tungstate $\left(\mathrm{PbWO}_{4}\right)$ films prepared by the polymeric precursor method and annealed at different temperatures were structurally characterized by means of x-ray diffraction and atomic force microscopy analysis. Quantum-mechanical calculations showed that the local disorder of the network modifier $(\mathrm{Pb})$ has a very important role in the charge transfer involved in the green PL emission. The experimental and theoretical results are in good agreement, both indicating that the generation of the intense visible PL band is related to simultaneous structural order and disorder in the scheelite $\mathrm{PbWO}_{4}$ lattice.
\end{abstract}

DOI: 10.1103/PhysRevB.75.165105

PACS number(s): 71.15.Mb, 71.20.Nr, 71.23.An, 78.55.Ap

\section{INTRODUCTION}

There is an increasing demand for light-emitting devices for displays and communication. In many optoelectronic devices, noncrystalline semiconductors can replace crystalline ones, mainly when they present better optical properties.

Numerous investigations of the PL property of scheelite lead tungstate $\left[\mathrm{PbWO}_{4}(\mathrm{PWO})\right]$ crystals have been carried out for several decades. ${ }^{1-15}$ In particular, the undoped PWO crystal has attracted much interest because of plans to use it as a scintillation detector at the Large Hadron Collider in CERN. ${ }^{4,6,10,16-19}$

Nevertheless, the understanding of PWO spectral behavior is still debated and some problems are left unsolved. ${ }^{20-23}$ For example, numerous experimental works directed at identifying several types of defects and their spectral roles in PWO have recently been published. ${ }^{24-29}$

Particularly, there are discussions ${ }^{30,31}$ over the contribution of color centers to the photoluminescence (PL) emission band, mainly to the green emission band. Groenink and Blasse $^{2}$ and Korzhik's group ${ }^{4,7,32,33}$ concluded that the green emission originated from the $\left(\mathrm{WO}_{3}+F\right)$ center in undoped PWO crystal, where $F$ is an electron bound to a negative ion vacancy. Sokolenko et al. ${ }^{34}$ attributed the green-red emission to $\left(\mathrm{WO}_{3} \cdot V_{O}^{*}\right)$ oxygen-deficient complexes, and Sinelnikov et $a l .{ }^{35}$ suggest that the $\mathrm{WO}_{4}$ tetrahedra distorted upon the formation of oxygen vacancies $V_{O}^{*}$ are responsible for the green luminescence band. On the other hand, Shi and co-workers ${ }^{30,31,36}$ suggest the $\left(\mathrm{WO}_{4}+\mathrm{O}_{i}\right)$ center as the green luminescence center, while Huang et al. ${ }^{37}$ conclude that the interstitial oxygen $\mathrm{O}_{i}$ enhances the green luminescence. These different interpretations are supported by distinct synthesis conditions and methods so that they are not contradictory but rather complementary.

Although there have been numerous studies on the PWO material, the literature has not yet reported on the PL prop- erty in noncrystalline (structurally disordered) PWO.

In this paper, we present measurements of an intense and broad visible PL band at room temperature in structurally disordered PWO thin films that have undergone insufficient thermal annealing to reach crystallization. These thin films were prepared by means of polymeric precursor method. ${ }^{38-41}$ This process offers advantages over several synthesis techniques such as low cost, good compositional homogeneity, high purity, low processing temperatures, and the ability to coat large substrate areas. The origin of the intense and broad PL band in PWO compound containing simultaneous structural order and disorder (order-disorder) in its lattice is investigated in terms of electronic structure calculations realized in the framework of ab initio periodic quantummechanical techniques. The aim of our synergistic strategy between experimental and theoretical results is not to explain all the possible PL mechanisms that occur during the photon excitation and decay processes, as many valid hypotheses already exist in the literature, but to discuss the role of structural order-disorder in the PL mechanism and why it provides favorable conditions for the generation of an intense and broad band.

The layout of the paper is as follows: In Sec. II, the experimental methods of the PWO preparation are described, together with spectral measurement techniques. Section III presents the computational details, while Sec. IV gives the crystal structure and periodic models used in the calculations. In Sec. V, the results are discussed, attempting to explain that the PL emission depends from the structural orderdisorder degree in the PWO lattice. Finally, Sec. VI resumes the main lines of our hypothesis on the origin of the strong $\mathrm{PL}$ at room temperature in PWO thin films.

\section{EXPERIMENT}

The flowchart of the PWO synthesis used in this study is outlined in Fig. 1. Tungsten citrate was formed by dissolu- 


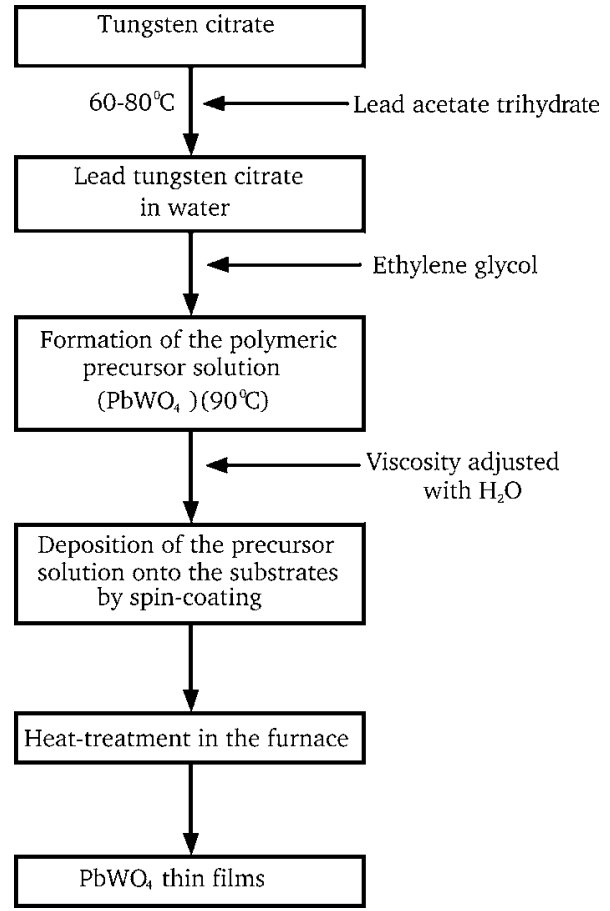

FIG. 1. Flowchart illustrating the procedure for the preparation of the PWO solution and thin-film production.

tion of tungstic acid $\left(\mathrm{H}_{2} \mathrm{WO}_{4}\right)$ in an aqueous solution of citric acid under constant agitation to homogenize the tungsten citrate solution. After homogenization of this solution, $\mathrm{Pb}\left(\mathrm{CH}_{3} \mathrm{CO}_{2}\right)_{2}$ salt was slowly added. The complex was well stirred for several hours at $70-80{ }^{\circ} \mathrm{C}$ to produce a clear, homogeneous solution. Lead acetate trihydrate was dissolved in water and a stoichiometric amount added to the tungsten citrate solution. Ammonium hydroxide was used to adjust the $p \mathrm{H}$ of the solution $(p \mathrm{H} \mathrm{5-6)}$ and to prevent precipitation of lead citrate. After the solution containing $\mathrm{Pb}$ was homogenized, ethylene glycol was added to promote the citrate polymerization by the polyesterification reaction. With continuous heating at $80-90{ }^{\circ} \mathrm{C}$, the solution became more viscous without any visible phase separation. The molar ratio between the cations lead and tungsten was 1:1 and that between citric acid and ethylene glycol was fixed at 60:40 (mass ratio). The viscosity of the deposition solution was adjusted to $15 \mathrm{mPas}$ by controlling the water content. The polymeric precursor solution was spin coated on silicon substrates by a spinner operating at $7000 \mathrm{rpm}$ for $40 \mathrm{~s}$ using a commercial spinner (spin coater KW-4B, Chemat Technology). The polymeric precursor solution was deposited onto the substrates via a syringe filter to avoid particulate contamination. After being spun onto the substrates, the films were kept in ambient air at $150{ }^{\circ} \mathrm{C}$ on a hot plate for $20 \mathrm{~min}$ to remove residual solvents. After the preannealing, the films were annealed at 200, 300, 400, and $500{ }^{\circ} \mathrm{C}$ for $4 \mathrm{~h}$ in air atmosphere.

The film thickness was controlled by adjusting the number of coatings, and each layer was pyrolyzed at $200{ }^{\circ} \mathrm{C}$ before the next layer was coated. These coating and/or drying operations were repeated until the desired thickness was obtained.
The PWO thin films were structurally characterized by $\mathrm{x}$-ray diffraction (XRD) using $\mathrm{Cu} K \alpha$ radiation source. The diffraction patterns were recorded on a Siemens D5000 machine in a $\theta-2 \theta$ configuration using a graphite monochromator. The spectral dependence of optical absorbance for the crystalline and disordered PWO thin films was measured in the transmission mode from 200 to $800 \mathrm{~nm}$ using a Cary 5G spectrophotometer. The PL spectra of the PWO thin films were recorded with a U1000 Jobin-Yvon double monochromator coupled to a cooled GaAs photomultiplier and a conventional photon counting system. The $488 \mathrm{~nm}$ excitation wavelength of an argon-ion laser was used, with the laser's maximum output power kept at $60 \mathrm{~mW}$. A cylindrical lens was used to prevent the sample from overheating. The slit width used was $100 \mu \mathrm{m}$. Atomic force microscopy (AFM) was used to obtain a three-dimensional image reconstruction of the sample surface. The image allows an accurate analysis of the sample surface and quantification of highly relevant parameters such as roughness and grain diameter. A Digital Instruments MultiMode Nanoscope IIIa was used. All measurements were taken at room temperature.

\section{COMPUTATIONAL METHODS}

Calculations were carried out with the CRYSTAL03 package ${ }^{42}$ within the framework of the density-functional theory using the gradient-corrected correlation functional by Lee, Yang, and Parr combined with the Becke3 exchange functional, ${ }^{43,44}$ (B3LYP) that was demonstrated by $\mathrm{Hu}$ and Chong $^{45}$ to be suitable for calculating structural parameters and band structures for a wide variety of solid-state compounds. The atomic centers have been described by pseudopotential basis sets Durand $-21 \mathrm{G}^{*}$ and $8-51 \mathrm{G}^{*}$ for $\mathrm{Pb}$ and $\mathrm{W}$, respectively. The oxygen atom is described by all electron basis set $6-31 \mathrm{G}^{*}$. The basis sets are taken from Ref. 46 . The $k$-point sampling was chosen to be 36 points within the irreducible part of the Brillouin zone. The program OPTIM (Ref. 47) was used to optimize the a and cell parameters. OPTIM is a general optimization tool that minimizes a chosen function that in this case is the computed total energy. The initial values of the cell parameters and oxygen fractional atomic positions $(x, y$, and $z)$ in the optimization process were obtained from experimental data. ${ }^{48,49}$

The XCRYSDEN (Ref. 50) program was used as a graphical tool for ploting the band-structure diagrams.

\section{CRYSTAL STRUCTURE AND PERIODIC MODELS}

The scheelite PWO crystallizes in a tetragonal structure, with space group $I 4_{1} / \mathrm{a}$. Tungsten atoms are surrounded by four oxygen atoms in a tetrahedral configuration, and lead atoms are surrounded by eight oxygen atoms in a pseudocubic configuration. The experimental and optimized values of the cell parameters and oxygen fractional atomic positions are presented in Table I. The fractional atomic positions of $\mathrm{Pb}$ and $\mathrm{W}$ atoms are $(0,1 / 4,5 / 8)$ and $(0,1 / 4,1 / 8)$, respectively.

For computational simplification, the CRYSTAL03 code works in the primitive unit cell rather than in the conven- 
TABLE I. Cell parameters and oxygen fractional atomic positions.

\begin{tabular}{lccccc}
\hline \hline & $\mathbf{a}$ & $\mathbf{c}$ & & & \\
& $(\AA)$ & $(\AA)$ & $\mathbf{x}$ & $\mathbf{y}$ & $\mathbf{z}$ \\
\hline Expt. $^{\mathrm{a}}$ & $5.456(2)$ & $12.020(2)$ & & & \\
Expt. $^{\text {b }}$ & & & $0.25(2)$ & $0.13(2)$ & $0.075(2)$ \\
Calc. & 5.31929 & 11.89434 & 0.22937 & 0.10342 & 0.04316 \\
\hline \hline
\end{tabular}

${ }^{\text {aReference } 48 .}$

${ }^{b}$ Reference 49.

tional one. We have used a primitive cell as a periodic model for representing the crystalline PWO (PWO-c). It results in 12 atoms (two $\mathrm{Pb}$, two $\mathrm{W}$, and eight $\mathrm{O}$ atoms); see Fig. 2(a).

Our aim is to compare the electronic structure of the crystalline model with models representing thin films before the complete crystallization, even if few structural information is available. We suppose that before the full crystallization of the film, i.e., before the annealing temperature reaches $500{ }^{\circ} \mathrm{C}$, the PWO lattice is composed of an aleatory mixture of $\mathrm{WO}_{3}$ (or distorted $\mathrm{WO}_{4}$ ) and regular $\mathrm{WO}_{4}$ clusters linked by the $\mathrm{Pb}$ ions. We also suppose that some $\mathrm{Pb}$ ion coordination spheres can be distorted in the lattice.

Besides the first PWO-c crystalline model, we created two other periodic models to simulate the PWO compounds containing simultaneously structural order and disorder in their lattice. The second model was created to displace the $\mathrm{Pb} 2$ atoms $0.4 \AA$ in the direction opposite to the $\mathrm{O} 2$ oxygen atom, as shown in Fig. 2(b). This periodic model is labeled PWO-p. Starting from the previous PWO-c crystalline model, the $\mathrm{W} 2$ and $\mathrm{Pb} 2$ atoms were displaced by 0.3 and $0.4 \AA$ in the direction opposite to the $\mathrm{O} 1$ and $\mathrm{O} 2$ oxygens, respectively. This third model is labeled PWO-pw, as shown in Fig. 2(c).

Many values were tested for the atomic displacements in PWO-p and PWO-pw models. The electronic structures of the models with different displacements are similar: although the results are quantitatively different, they do not influence the conclusions of this work, which aim to compare various disorder possibilities.

Our proposal regarding the use of these models is to offer a simple scheme enabling an understanding of the effects of structural deformations on the electronic structure because the most intense PL emission is evidenced in PWO samples containing structural order-disorder, without completely re- moving the symmetry of the unit cell, which is useful for the periodic calculations. We are aware that they do not represent the exact structures of order-disordered PWO lattice. We are focusing on the effect of periodic local structural deformation among the numerous possible irregularities. This strategy of models with the coexistence of different types of environments around the network former has already been successfully employed in studying the PL emission in orderdisordered structures of scheelite tungstates ${ }^{51-53}$ and of perovskite titanates. ${ }^{54-59}$ In the case of the perovskite titanates, the cationic environments had fivefold $M_{5}(M=\mathrm{Ti}, \mathrm{Zr})$ and sixfold $M_{6}$ coordinations. In the present paper, we introduce one more deformation around the network modifier, and we observe that the effect on the electronic structure is decisive for the PL mechanism, whereas the existing hypothesis focuses on the network former.

\section{RESULTS AND DISCUSSION}

\section{A. Structural analysis}

Figure 3 presents the x-ray diffraction patterns, recorded at room temperature, of PWO thin films heat treated at 200, 300,400 , and $500{ }^{\circ} \mathrm{C}$ for $4 \mathrm{~h}$ in air atmosphere. A diffuse pattern is observed for the sample treated at $200^{\circ} \mathrm{C}$, indicating the formation of a highly disordered inorganic structure after the pyrolysis process. The sample treated at $300^{\circ} \mathrm{C}$, similar to the sample treated at $200{ }^{\circ} \mathrm{C}$, still does not present any diffraction peak. Some broad diffraction peaks of the scheelite phase are already visible for the sample heat treated at $400{ }^{\circ} \mathrm{C}$, indicating that in these conditions of annealing, structural order-disorder is present in the lattice. The diffraction peaks are more visible and well defined for the film treated at $500{ }^{\circ} \mathrm{C}$.

No additional nor intermediate phases were detected in the PWO thin films, suggesting a direct crystallization process from the highly disordered structure (heat treated up to $200{ }^{\circ} \mathrm{C}$ ) to crystalline phase (heat treated up to $500{ }^{\circ} \mathrm{C}$ ) by thermal treatment. All diffraction peaks are ascribed to the scheelite tetragonal structure (space group $I 4_{1} / a, C_{4 h}^{6}$ symmetry), matching with the pattern in Ref. 71.

The Cross section of the film layers revealed a uniform microstructure throughout the film thickness of about $300 \mathrm{~nm}$.

Figure 4 presents the images of surface morphology of the PWO thin films from AFM measurements. The samples heat

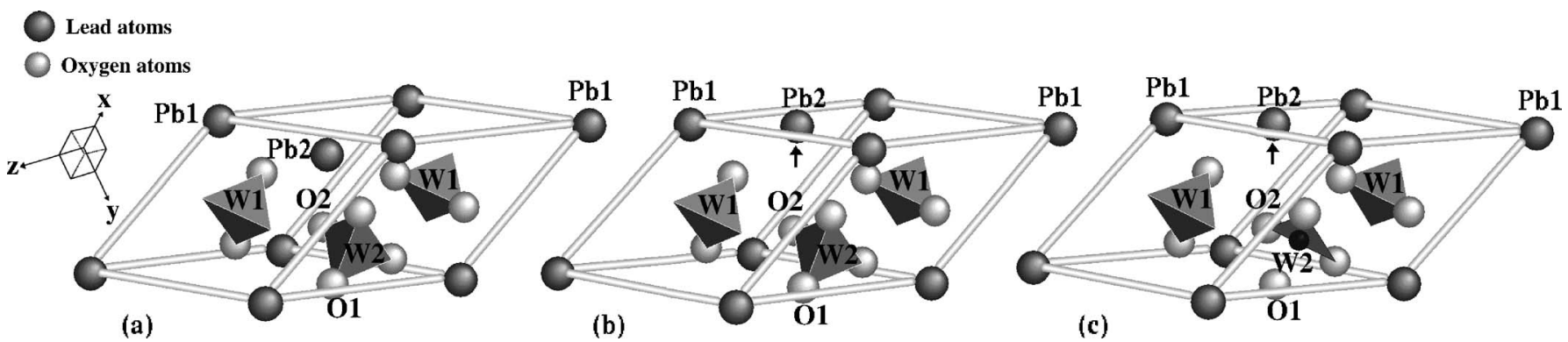

FIG. 2. (a) PWO-c crystalline, (b) PWO-p, and (c) PWO-pw primitive unit-cell periodic models of the PWO structure. Arrows show the direction of $\mathrm{Pb} 2$ displacements. 


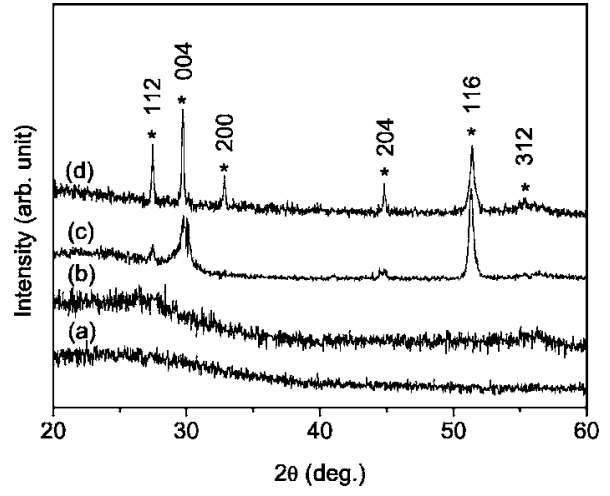

FIG. 3. XRD patterns measured at room temperature for the PWO thin films heat treated at (a) 200, (b) 300, (c) 400, and (d) $500{ }^{\circ} \mathrm{C}$ for $4 \mathrm{~h}$ in air atmosphere.

treated at 200 and $300{ }^{\circ} \mathrm{C}$ present a homogeneous surface morphology with very low roughness. There was no evidence of a granular structure, as seen in Figs. 4(a) and 4(b). Table II presents the evolution of the roughness and of the average grain diameter of the PWO samples measured by means of AFM analysis. Such analysis indicates that the PWO thin film heat treated at $400{ }^{\circ} \mathrm{C}$ has a homogeneous nucleation leading to a grain diameter distribution of approximately 50-60 nm. The image in Fig. 4(c) evidences an increase in roughness, indicating the ordering in the structure. The surface morphology of the film treated at $500{ }^{\circ} \mathrm{C}$ changes dramatically, indicating a high degree of structural order in the lattice. The coalescence of nuclei occurs for the samples treated at 400 and $500{ }^{\circ} \mathrm{C}$ with the formation of granular structures, resulting in a significant increase in roughness as presented in Table II and observed in Figs. 4(c) and 4(d). and This result is in agreement with the XRD mea-
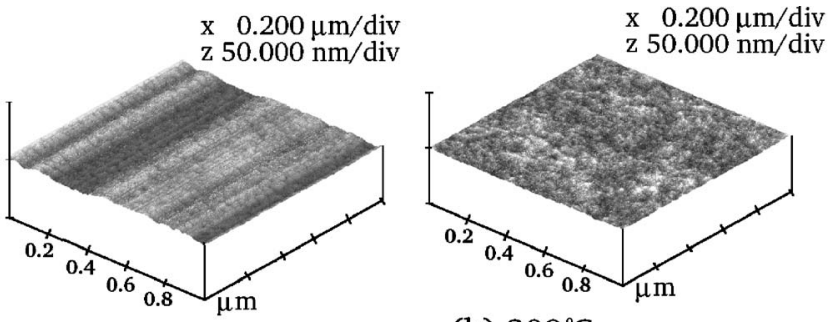

(a) $200^{\circ} \mathrm{C}$

(b) $300^{\circ} \mathrm{C}$

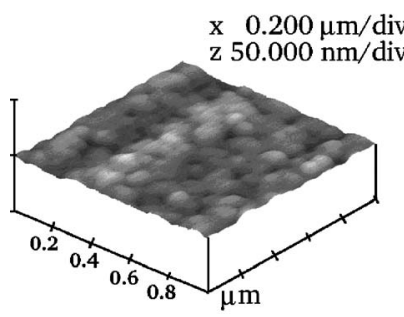

(c) $400^{\circ} \mathrm{C}$

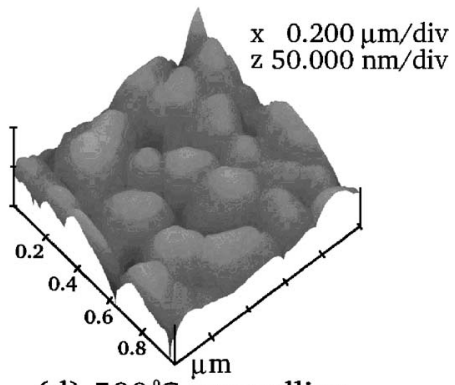

(d) $500^{\circ} \mathrm{C}$, crystalline

FIG. 4. AFM images measured at room temperature for the PWO thin films heat treated at (a) 200, (b) 300, (c) 400, and (d) $500{ }^{\circ} \mathrm{C}$.
TABLE II. Roughness and average grain diameter evolution with the structural ordering of the PWO thin films.

\begin{tabular}{lcccc}
\hline \hline Annealing temperatures $\left({ }^{\circ} \mathrm{C}\right)$ & 200 & 300 & 400 & 500 \\
Roughness $(\mathrm{nm})$ & 0.41 & 0.42 & 1.15 & 9.31 \\
Average grain diameter $(\mathrm{nm})$ & & & $50-60$ & $260-270$ \\
\hline \hline
\end{tabular}

surement of PWO thin film heat treated at $500{ }^{\circ} \mathrm{C}$ in which a high structural order degree can be observed.

\section{B. Band-gap measurements and calculations}

The absorbance spectra of the PWO thin films annealed at 300,400 , and $500{ }^{\circ} \mathrm{C}$ are presented in Fig. 5. The values of the gap energies can be obtained by means of the method of Wood and Tauc. ${ }^{60}$ The gap energies of the PWO thin films treated at 500,400 , and $300{ }^{\circ} \mathrm{C}$ are $4.5,4.4$, and $4.1 \mathrm{eV}$, respectively. This decrease of the gap energy value was associated by Wood and Tauc with the existence of localized states in the band gap due to structural defects. This behavior indicates that the density of localized states in the band gap of the film heat treated at $300{ }^{\circ} \mathrm{C}$ is greater than those of the corresponding films heat treated at 400 and $500{ }^{\circ} \mathrm{C}$ due the higher structural disorder in the film treated at $300^{\circ} \mathrm{C}$.

Band dispersions for the PWO-c, PWO-p, and PWO-pw models are plotted along five symmetry directions within the primitive body-centered-tetragonal Brillouin zone ${ }^{61}$ (Fig. 6), as presented in Fig. 7.

Figure 7(a) features the calculated band structure for the PWO-c model. The top of the valence band (VB) is located on the $\Delta$ direction, between $X$ and $\Gamma$ point. The bottom of the conduction band (VB) is on the $\Sigma$ segment. The crystalline PWO thus present an indirect band gap between $\Delta$ and $\Sigma$, as already observed by Zhang et al. who have investigated in detail the electronic band structures of the crystalline scheelites $\mathrm{PbWO}_{4}, \mathrm{PbMoO}_{4} \mathrm{CaWO}_{4}$, and $\mathrm{CaMoO}_{4}$, by means of calculations performed with the linearized-

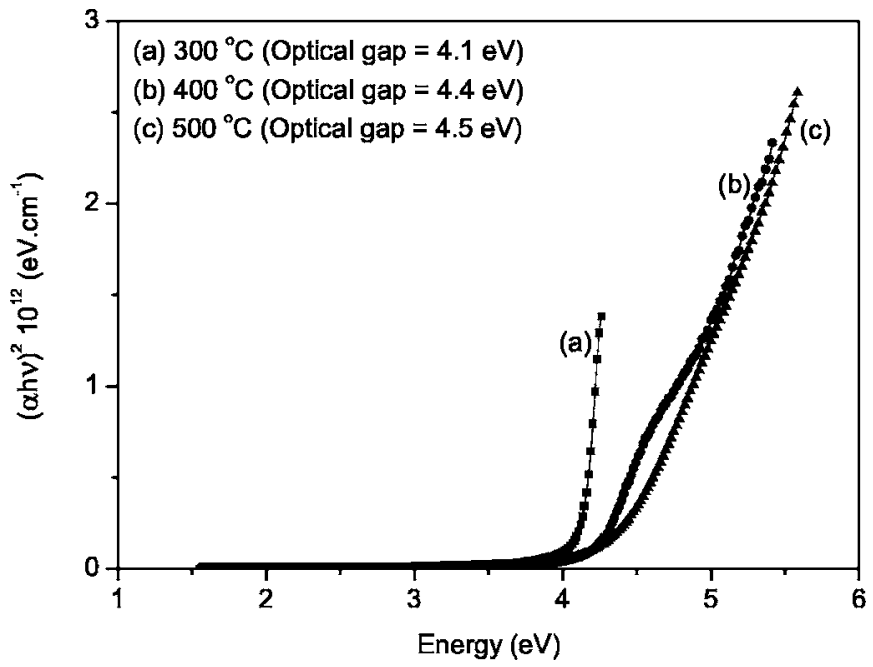

FIG. 5. Spectral dependence of the absorbance at room temperature for the PWO thin films heat treated at (a) 300, (b) 400, and (c) $500{ }^{\circ} \mathrm{C}$. 


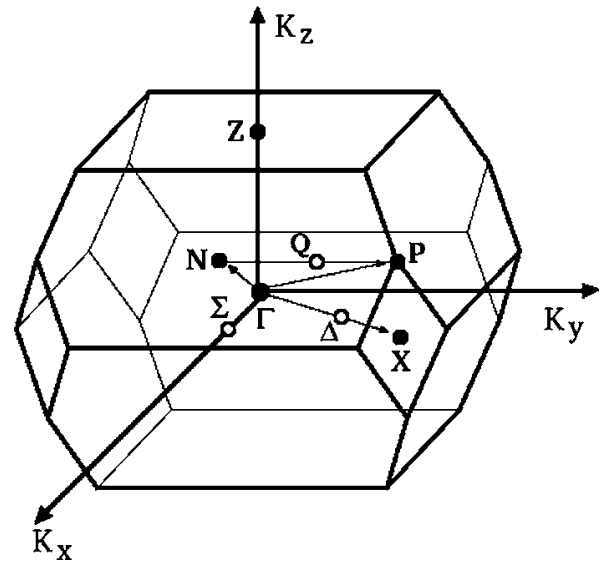

FIG. 6. Diagram of the primitive body-centered-tetragonal Brillouin zone based on Ref. 61.

augmented plane-wave technique. ${ }^{62}$ They calculated an indirect gap energy of $2.96 \mathrm{eV}$ for PWO and our method leads to $4.19 \mathrm{eV}$, closer to the experimental value $(4.5 \mathrm{eV})$. This is due to our B3LYP functional known to be the best for describing the oxide materials. ${ }^{45}$

In Fig. 7(b), for the periodic model PWO-p in which only the network modifier $\mathrm{Pb}$ was displaced, the top of the $\mathrm{VB}$ and the bottom of the $\mathrm{CB}$ are also located on the $\Delta$ and $\Sigma$

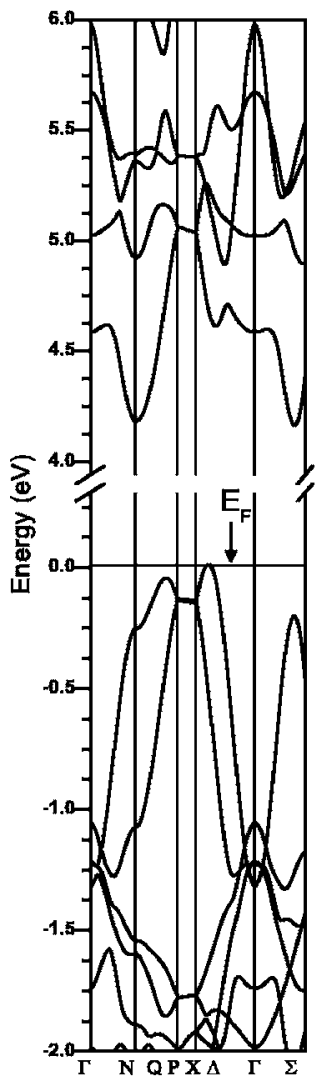

(a)

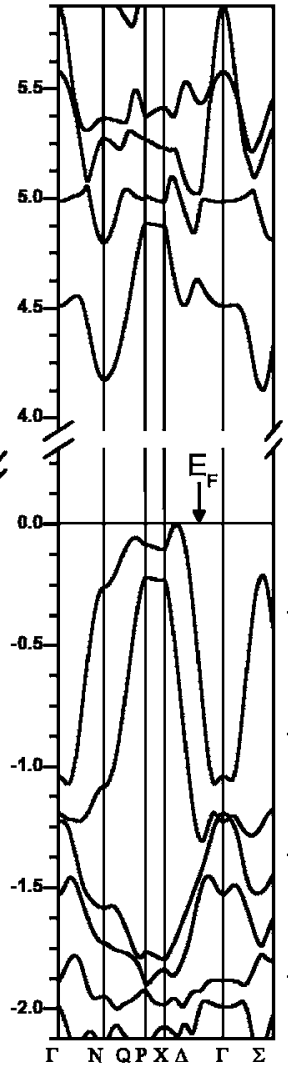

(b)

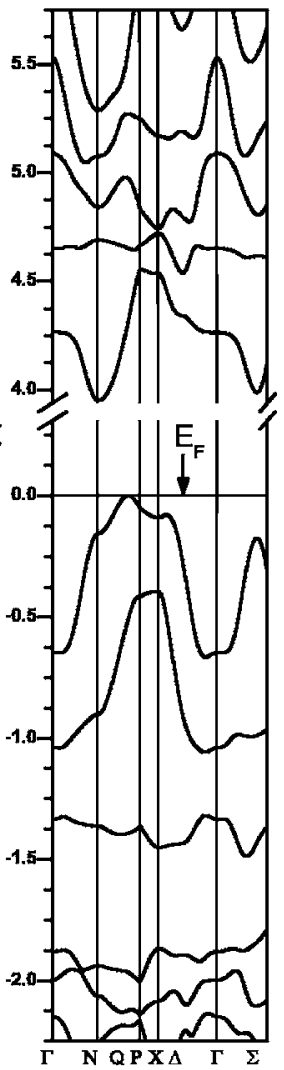

(c)
FIG. 7. Calculated band structure for the (a) PWO-c, (b) PWO-p, and (c) PWO-pw models. The zero has been set to the Fermi energy $E_{F}$ at the last occupied band to each model. directions, respectively. The degeneracy existing for the PWO-c model between $P$ and $X$ is broken in this case for both the VB and the CB. This is due to the symmetry perturbation linked to the displacement of $\mathrm{Pb}$ atom. As for the band structure of the PWO-c crystalline model [Fig. 7(a)], there are two crossing points in the $\mathrm{CB}$ around the $\Gamma$ point and one crossing point in the $\Gamma \rightarrow N$ direction. In the $\mathrm{VB}$, the crossings are avoided. The most energetic band of the VB jumps much more into the band gap than that of the crystalline model (PWO-c). Its band gap of $4.12 \mathrm{eV}$ is very close to the one calculated for the PWO-c model.

In Fig. 7(c), the PWO-pw model also presents an indirect band gap, but with the top of the VB and the bottom of the CB located in the $Q$ direction along the $N \rightarrow P$ line and at the $N$ point, respectively. The band structure of the PWO-pw model does not present any crossing point in the considered energy range; the symmetry has been deeply perturbed by the $\mathrm{Pb}$ and $\mathrm{W}$ displacements. There is also a bigger jump of the most energetic band of the VB in the band gap. This fact shows that the displacement of the tungsten modifies the PWO electronic structure, as expected, because it is well known that the details of the band structure in a solid are mainly determined by the potential within the unit cell rather than by the long-range periodicity. It is interesting to observe the shape of the highest occupied band. This band and the one immediately beneath are of $2 p(\mathrm{O})$ character and depend on the $\mathrm{W}-\mathrm{O}$ bond. A displacement of $\mathrm{W}$ alters the overlap between $2 p(\mathrm{O})$ and $5 d(\mathrm{~W})$ crystsal orbitals, i.e., it modifies the way the corresponding bands run. The indirect band gap of the PWO-pw model is calculated to be $3.93 \mathrm{eV}$, smaller than the band gap of the PWO-p model. The gap energies of the PWO-p and PWO-pw models diminish due to the jump of the upper levels of VB above the highest band of VB in the PWO-c electronic structure. These levels located in the band gap are linked to the structural disorder degree introduced by the displacements of the $\mathrm{Pb}$ and $\mathrm{W}$ atoms, and were already suggested by the absorbance measurements presented on Fig. 5, where the structurally order-disordered PWO thin films (treated at 300 and $400{ }^{\circ} \mathrm{C}$ ) presented smaller gap energies than the gap energy of the crystalline thin film (treated at $500{ }^{\circ} \mathrm{C}$ ).

To investigate the dominant characters in the bands surrounding the band gap, Fig. 8 schematically illustrates the energy levels for the three proposed models. A coefficient square modulus of 0.15 has been chosen as threshold for selecting the main orbital contributions. The energy levels are representative of bands at the $\mathrm{VB}$ top and $\mathrm{CB}$ bottom points for each respective model. In this way, the VB levels for the PWO-c and PWO-p models are taken at the highest $\Delta$ point and at the highest $Q$ point for the PWO-pw model. The CB levels for the PWO-c and PWO-p models are taken at the lowest $\Sigma$ point and at the $N$ point for the PWO-pw model.

For the PWO-c crystalline model [Fig. 8(a)], the upper VB is mainly formed by $2 p$ and $6 s$ orbitals of the oxygen and lead atoms, respectively. The $2 p\left(2 p_{x}, 2 p_{y}, 2 p_{z}\right)$ orbitals equivalently originate from each oxygen atom, and the $6 \mathrm{~s}$ orbital from the lead atoms. The $6 s$ states of the $\mathrm{Pb}$ atoms contribute very little to the upper VB compared to the contributions of $2 p(\mathrm{O})$ states. The lower levels of the $\mathrm{CB}$ are dominated by $5 d z^{2}(\mathrm{~W}), 5 d x^{2}-y^{2}(\mathrm{~W}), 6 p\left(6 p_{x}, 6 p_{y}, 6 p_{z}\right)$ 


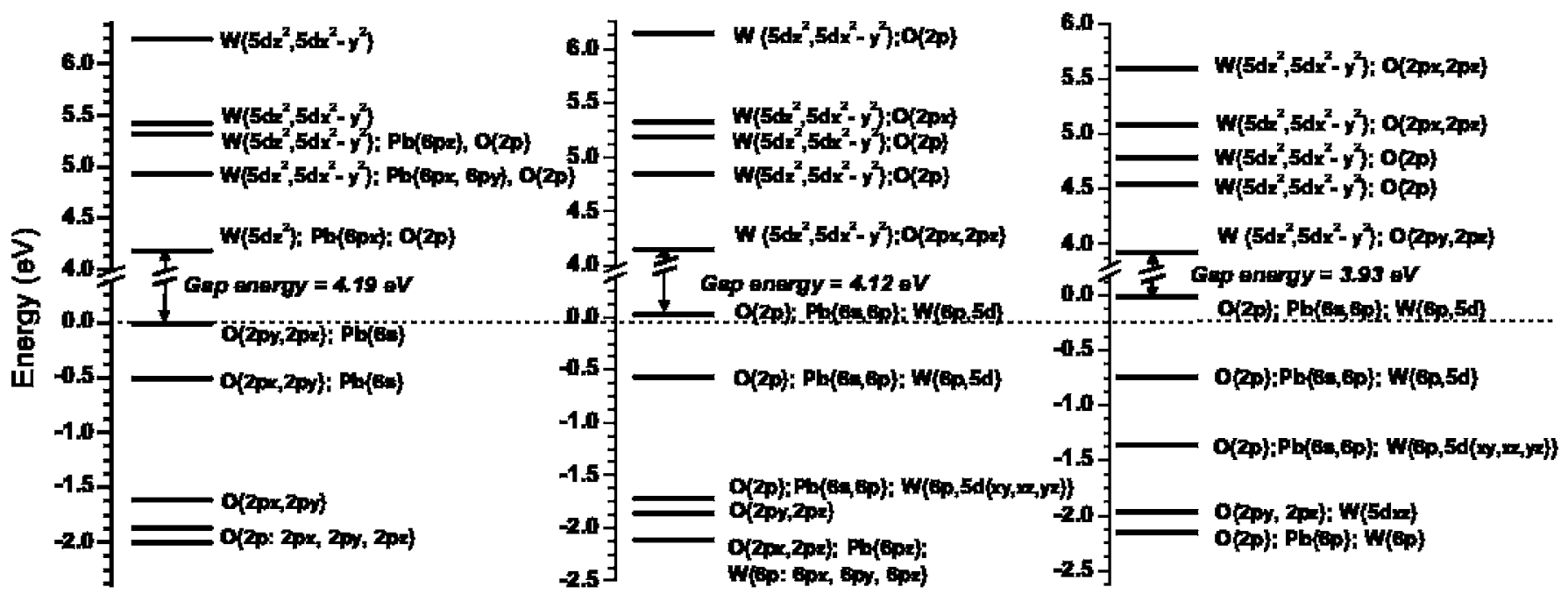

(a)

(b)

(c)

FIG. 8. Representation of the main atomic-orbital contributions at the highest valence-band points and the lowest conduction-band points for the (a) PWO-c, (b) PWO-p, and (c) PWO-pw models.

$(\mathrm{Pb})$, and $2 p(\mathrm{O})$ contributions, while the upper $\mathrm{CB}$ is dominated only by $e$-like $\left(5 d z^{2}, 5 d x^{2}-y^{2}\right)(\mathrm{W})$ contributions. The $e$-like $(\mathrm{W})$ states equivalently originate from every tungsten atom. This splitting of the $5 d(\mathrm{~W})$ orbitals corresponds to the regular tetrahedral environment of the tungsten in the scheelite structure. The tetrahedra are regular but the splitting is not the classical $e-t_{2}$ because they are not aligned along the $z$ axis like in the $T_{d}$ group. Although this representation is taken at a particular direction, it is in accordance with the partical densities of states for crystlline $\mathrm{PbWO}_{4}$ presented in Refs. 62 and 63.

For the PWO-p model, [Fig. 8(b)], the upper VB is dominated by the $2 p$ orbitals of the oxygen atoms and by the $6 s$ and $6 p$ orbitals of the $\mathrm{Pb}$ atoms. The $6 p$ and $5 d\left(5 d z^{2}\right.$, $5 d x^{2}-y^{2}, 5 d x z, 5 d y z, 5 d x y$ ) orbitals of the $\mathrm{W}$ atoms also contribute to the upper VB due the electronic perturbation enhanced by the displacement of the lead atom in each unit cell. The $2 p(\mathrm{O}), 6 p(\mathrm{~W}) 5 d(\mathrm{~W}), 6 s(\mathrm{~Pb})$, and $6 p(\mathrm{~Pb})$ states slightly rise from the VB above the band gap corresponding to the PWO-c model. These states located in the band gap can be called localized states. The bottom of the CB is dominated by $e$-like $(\mathrm{W})$ and $2 p(\mathrm{O})$ contributions. In this case, the $5 d(\mathrm{~W})$ states also contribute to the upper VB as if the hybridization between $\mathrm{O}$ and $\mathrm{W}$ states were reinforced by the displacement of the $\mathrm{Pb}$ atom.

For the PWO-pw model [Fig. 8(c)], the upper VB is dominated by the $2 p(\mathrm{O}), 6 p(\mathrm{~W}), 5 d(\mathrm{~W}), 6 s(\mathrm{~Pb})$, and $6 p$ $(\mathrm{Pb})$ states and the bottom of the $\mathrm{CB}$ is dominated by $e$-like $(\mathrm{W})$ and by $2 p(\mathrm{O})$ states. These observations are similar to those in the PWO-p model in the considered energy range, but the state destabilization is stronger due to the increase in the degree of structural disorder in the lattice and the breaking of one $\mathrm{W}-\mathrm{O}$ covalent bond controlling the frontier bands. The consequence is a bigger reduction of the gap energy by localized states.

At this stage, it has to be noted that Abraham et al. also presented density-functional theory calculations of irregular
PWO, ${ }^{63}$ but their results are difficult to compare with ours because they created oxygen vacancies in a supercell while we only displaced some atoms, keeping their total number constant.

\section{Photoluminescence measurements and interpretation}

Figure 9 illustrates the PL spectra recorded at room temperature for the PWO thin films heat treated at 200, 300, 400, and $500{ }^{\circ} \mathrm{C}$. They were excited by the $488 \mathrm{~nm}(\approx 2.54 \mathrm{eV})$ line of an argon-ion laser. They emit in the visible spectra region. The PL emission bands are broad and intense, mainly for the order-disordered thin films annealed at 300 and $400{ }^{\circ} \mathrm{C}$. These broad bands are typical of a multiphonon process, i.e., a system in which relaxation occurs by various paths, involving the participation of numerous states. The

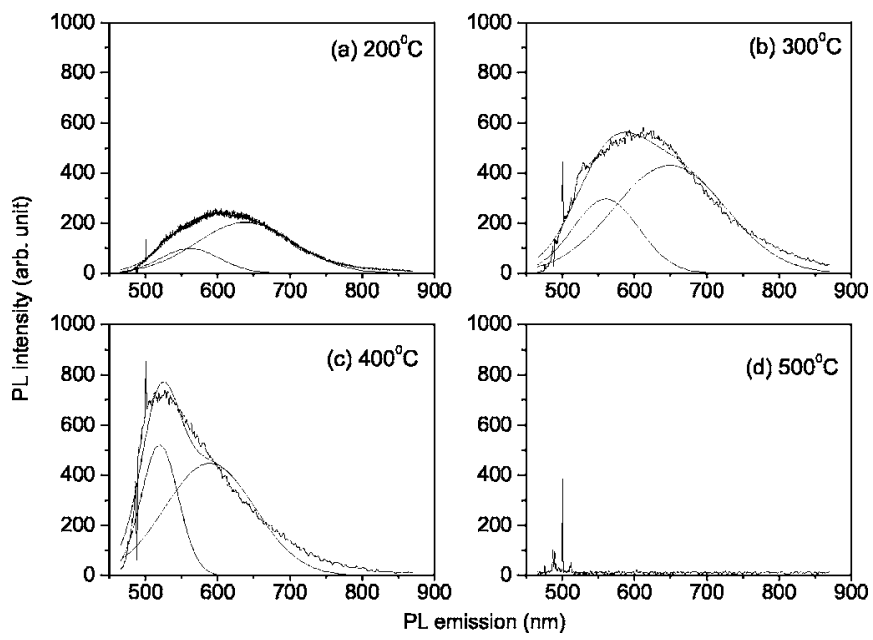

FIG. 9. Photoluminescence spectra at room temperature of the PWO thin films heat treated at (a) 200, (b) 300, (c) 400, and (d) $500{ }^{\circ} \mathrm{C}$. 
TABLE III. PL green fraction evolution with the structural order degree in PWO thin films. GA, RA, EA, and FA are areas of the green decomposed band, red decomposed band, experimental band and fitted band (experimental band fit), respectively.

\begin{tabular}{lccccccc}
\hline \hline Samples & Peak 1 (nm) & Peak 2 (nm) & GA/EA & RA/EA & GA/FA & RA/FA & FA/EA \\
\hline Sample annealed at $200{ }^{\circ} \mathrm{C}$ & 562 & 638 & 0.23 & 0.76 & 0.23 & 0.77 & 0.99 \\
Sample annealed at $300^{\circ} \mathrm{C}$ & 560 & 649 & 0.29 & 0.70 & 0.29 & 0.71 & 0.99 \\
Sample annealed at $400^{\circ} \mathrm{C}$ & 520 & 589 & 0.31 & 0.67 & 0.32 & 0.68 & 0.98 \\
Sample annealed at $500^{\circ} \mathrm{C}$ & & & & & & & \\
\hline \hline
\end{tabular}

crystalline thin film heat treated at $500{ }^{\circ} \mathrm{C}$ almost does not present PL emission. The most intense PL emission is obtained for the structure that is neither highly disordered (heat treated at $200{ }^{\circ} \mathrm{C}$ ) nor highly ordered (heat treated at $500{ }^{\circ} \mathrm{C}$ ), i.e., for the film treated at $400{ }^{\circ} \mathrm{C}$. This indicates that the PL intensity is linked to the structural order-disorder degree in the lattice.

The emission bands can be decomposed into two components, two broad bands, one with peak maximum in the range 520-562 nm (green), and another band with peak maximum in the range $589-649 \mathrm{~nm}$ (red), as presented in Fig. 9. The green band area represents $23 \%, 29 \%$, and $31 \%$ of the experimental PL band area for the thin films treated at 200, 300, and $400{ }^{\circ} \mathrm{C}$, respectively, as shown in Table III. The intensity of the PL emission increases (about 2.5 times) for the sample treated at $200{ }^{\circ} \mathrm{C}$ compared to the other treated at $300{ }^{\circ} \mathrm{C}$, increasing the green band area from $23 \%$ to $29 \%$ and decreasing the red band area from $76 \%$ to $70 \%$. The PWO sample treated at $400{ }^{\circ} \mathrm{C}$ presents the most intense PL band emission. For this sample, the green band area increases to $31 \%$ while the red band area decreases to $67 \%$. The decrease of the red emission fraction due the structural ordering has also been recently observed for perovskite titanates ${ }^{54,64}\left(\mathrm{CaTiO}_{3}: \mathrm{Sm}, \mathrm{PbZr}_{0.53} \mathrm{Ti}_{0.47} \mathrm{O}_{3}\right)$ and for scheelite tungstates ${ }^{52,53}\left(\mathrm{SrWO}_{4}, \mathrm{CaWO}_{4}\right)$.

The DRX diagrams, the AFM analysis, and the decompositions of the PL emission bands indicate that the red fraction of the emission band is related to the high structural disorder degree in the PWO lattice, because the smaller the heat treatment temperature (the greater the disorder degree), the greater the red emission fraction. The components of the PL emission band are probably linked to specific atomic arrangements.

Table IV presents the net charges of each individual cluster of the three periodic models and their respective gap energies. The charge analysis has been made following the Mulliken distribution, which is sufficient for our qualitative purpose. The $\mathrm{Pb}_{2} \mathrm{O}_{6}$ cluster is formed by a lead atom (labeled $\mathrm{Pb} 2$ in Fig. 2) and only six oxygen atoms due to the displacement of the $\mathrm{Pb} 2$ in the direction opposite to the oxygen atom labeled $\mathrm{O} 2$. The $\mathrm{W}_{2} \mathrm{O}_{3}$ cluster is formed by a tungsten atom labeled W2 and only three-oxygen atoms due the displacement of the $\mathrm{W} 2$ in the opposite direction to the oxygen atom labeled $\mathrm{O} 1$. The $\mathrm{Pb}_{10}, \mathrm{~Pb}_{2} \mathrm{O}_{8}, \mathrm{~W}_{1} \mathrm{O}_{4}$, and $\mathrm{W}_{2} \mathrm{O}_{4}$ clusters are regular clusters as illustrated in Fig. 2.

For the PWO-p model, the charge of the cluster around the displaced $\mathrm{Pb} 2$ atom $\left(\mathrm{Pb}_{2} \mathrm{O}_{6}\right.$ cluster) is positively increased by a local charge gain $\delta_{p}=+0.74|e|$, and a great local hole is induced by the loss of connection with two oxygen anions, compensated by electron gains on the other clusters belonging to the unit cell.

For the PWO-pw model, the charge of the $\mathrm{W}_{2} \mathrm{O}_{3}$ cluster is positively increased by a local charge gain $\delta_{p w}=+0.23|e|$ and the ${\mathrm{W} 1 \mathrm{O}_{4}}_{4}$ cluster has a negative local charge gain $\delta_{p w}$ $=-0.20|e|$. The charge in cluster of the $\mathrm{Pb} 2\left(\mathrm{~Pb}_{2} \mathrm{O}_{6}\right)$ is positively increased by a local charge gain $\delta_{p w}=+0.53|e|$. This

TABLE IV. Mulliken charges of clusters and indirect gap energies of the PWO periodic models.

\begin{tabular}{|c|c|c|}
\hline $\begin{array}{l}\text { Charges of the } \\
\text { PWO-c clusters }|e|\end{array}$ & $\begin{array}{l}\text { Charges of the } \\
\text { PWO-p clusters }|e|\end{array}$ & $\begin{array}{c}\text { Charges of the } \\
\text { PWO-pw clusters }|e|\end{array}$ \\
\hline $\mathrm{Pb} \mathrm{O}_{8}:-1.91$ & $\mathrm{~Pb}_{10}:-2.27$ & $\mathrm{~Pb}_{10}:-2.47$ \\
\hline $\mathrm{Pb}_{2} \mathrm{O}_{8}:-1.91$ & $\mathrm{~Pb}_{2} \mathrm{O}_{6}:-1.17$ & $\mathrm{~Pb} 2 \mathrm{O}_{6}:-1.38$ \\
\hline 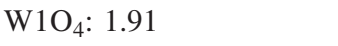 & $\mathrm{W} 1 O_{4}: 1.72$ & $\mathrm{~W} 1 O_{4}: 1.71$ \\
\hline $\mathrm{W}_{2} \mathrm{O}_{4}: 1.91$ & $\mathrm{~W} 2 \mathrm{O}_{4}: 1.72$ & $\mathrm{~W}_{2} \mathrm{O}_{3}: 2.14$ \\
\hline $\begin{array}{l}\text { Local charge gains } \delta_{c} \\
\text { of the PWO-c clusters }|e|\end{array}$ & $\begin{array}{l}\text { Local charge gains } \delta_{p} \\
\text { of the PWO-p clusters }|e|\end{array}$ & $\begin{array}{l}\text { Local charge gains } \delta_{p w} \\
\text { of the PWO-pw clusters }|e|\end{array}$ \\
\hline $\mathrm{Pb} \mathrm{O}_{8}: 0.00$ & $\mathrm{~Pb}_{10}:-0.36$ & $\mathrm{~Pb}_{10}:-0.56$ \\
\hline $\mathrm{Pb}_{2} \mathrm{O}_{8}: 0.00$ & $\mathrm{~Pb}_{2} \mathrm{O}_{6}:+0.74$ & $\mathrm{~Pb}_{2} \mathrm{O}_{6}:+0.53$ \\
\hline $\mathrm{W}_{10}: 0.00$ & $\mathrm{~W} 1 O_{4}:-0.19$ & $\mathrm{~W}_{10}:-0.20$ \\
\hline $\mathrm{W}_{2} \mathrm{O}_{4}: 0.00$ & $\mathrm{~W}_{2} \mathrm{O}_{4}:-0.19$ & $\mathrm{~W}_{2} \mathrm{O}_{3}:+0.23$ \\
\hline Gap energy $=4.19 \mathrm{eV}$ & Gap energy $=4.12 \mathrm{eV}$ & Gap energy $=3.93 \mathrm{eV}$ \\
\hline
\end{tabular}




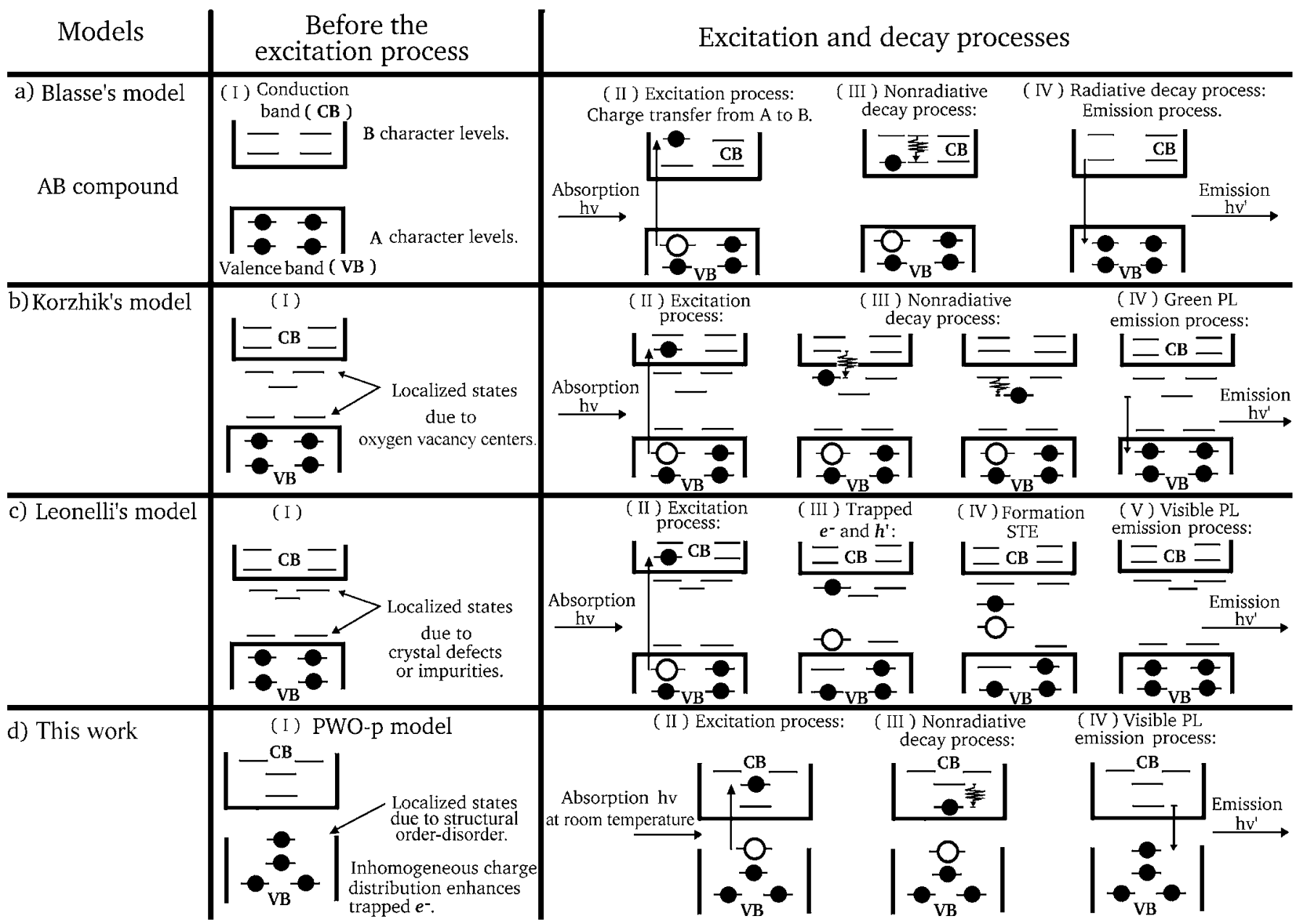

FIG. 10. Different models for the interpretation of the wide band photoluminescence phenomenon. (a) Blasse's model, charge transfer from atom A to B. (b) Korzhik's model, localized states due to centers related to oxygen vacancies act as intermediary step in the radiative decay processes. (c) Leonelli's model proposed the self-trapped excitons (STE) formation contributing to the visible PL emission during the decay process. (d) The PWO-p model: localized states, trapped holes, and electrons due to structural order-disorder before any excitation, thanks to inhomogeneous charge distribution, where $h \nu$ is excitation energy and $h \nu^{\prime}$ are emission energies forming the broad PL band.

charge gain of the $\mathrm{Pb}_{2} \mathrm{O}_{6}$ cluster is smaller than the charge gain of the $\mathrm{Pb}_{2} \mathrm{O}_{6}$ cluster in the model PWO-p, because the displacement of W2 tungsten atom induces a charge compensation. These results point out that the local hole is greater in the case of one local deformation (PWO-p) than in the case of two local deformations (PWO-pw) in each unit cell due to the charge compensations by other adjacent clusters. This behavior indicates that the structures containing a lesser degree of structural disorder have greater local holes and consequently are more favorable for the intense PL emission, because great local holes are more favorable to electron transfers when submitted to photon excitation.

The structural transformations occurring from disordered to ordered phases start from the early stage of the polyesterification of the citrate solution containing the tungsten and lead ions. The crystallization process occurs by heat treatment. The tungsten atom tends ideally to bond with four oxygen atoms $\left(\mathrm{WO}_{4}\right)$, and the lead atom tends ideally to bond with eight oxygen atoms $\left(\mathrm{PbO}_{8}\right.$ pseudocubic configuration). The tungsten, which is the lattice former, organizes sooner than the lead. In the structure just before the complete crystallization there exist various coordination environments for the $\mathrm{Pb}$ while the tungsten clusters are already regular. The PWO structure annealed at $400{ }^{\circ} \mathrm{C}$, just before complete crystallization, presented a favorable condition for the most intense PL emission. When the crystallization is reached, only $\mathrm{WO}_{4}$ and $\mathrm{PbO}_{8}$ regular clusters exist and the PL vanishes, showing that a complete order is not suitable for intense visible PL emission at room temperature.

The visible PL spectra show that the highly disordered and highly ordered structures are not favorable for an intense PL emission. It should be underlined that the excitation energy used $(2.54 \mathrm{eV} ; 488 \mathrm{~nm})$ is smaller than that corresponding to the $420 \mathrm{~nm}(\approx 2.95 \mathrm{eV})$ blue emission frequently attributed in the literature to the $\mathrm{WO}_{4}$ regular tungstate group, ${ }^{4,30-32,65}$ and for this reason cannot be observed.

The quantum-mechanical theoretical and absorbance spectra analyses point out that the apparition of localized states in the band gap of order-disordered PWO structures and the increase of the structural disorder degree diminish the gap energy, as seen in Table IV and Fig. 5. The structural disorder can favor PL emission with excitation energy 
smaller than the crystalline gap energy. But this sole effect is insufficient for enhancing the intense visible PL at room temperature, as can be seen in the more disordered sample (treated at $200{ }^{\circ} \mathrm{C}$ ) which presents a smaller PL intensity than the other order-disordered samples (treated at 300 and $400{ }^{\circ} \mathrm{C}$ ). The experimental gap energies of the PWO thin films containing structural order-disorder are higher than the excitation energy used for collecting the PL spectra $(2.54 \mathrm{eV}$, $488 \mathrm{~nm}$ ); such observation confirms the fact pointed out by Montoncello et al. ${ }^{66}$ that PL often highlights features that absorption measurements would rarely define as the properties of the energy levels lying within the band gap of a material.

The charge gradient (polarization) and the presence of the localized states provide very good conditions for the trapping of electrons and holes, which can allow PL radiative recombination in the structurally order-disordered compounds. As explained by Blasse and Grabmaier, ${ }^{3}$ the PL arises from a radiative return to the ground state, a phenomenon that is enhanced by the presence of charge trapping at room temperature. Blasse and Grabmaier indeed showed the PL behavior of perovskite-type oxides at low temperature (45 K), where less energy is lost for the vibration of the lattice so that the radiative recombination is encouraged. At room temperature, however, if no charge trapping promotes the radiative recombination, the energy is used for the lattice vibrations.

Figure 10 compares some models exposed by different authors to explain their views on the PL emission. We compare them before the photon excitation process with the PWO-p model for illustrating that the structural orderdisorder is a favorable condition to PL emission. It has to be emphasized that other authors have proposed PL mechanism models frequently dealing with low-temperature measurements and have barely discussed the conditions prior to excitation. In the present study, the synergistic analysis of experimental and theoretical results shows that the keys to an efficient photoluminescence emission at room temperature are defined before excitation.

The model proposed by Blasse and co-workers ${ }^{3,67,68}$ is based on a charge transfer from the atom having its main contribution in the VB to the atom forming the CB. The different steps of the process are depicted in Fig. 10(a).

Korzhik et al. ${ }^{7}$ have assumed that localized states linked to local defects such as oxygen vacancies exist in the band gap for the undoped crystalline PWO compound. During the excitation and radiative decay processes, those levels are used as intermediary steps [Fig. 10(b)] and some of them contribute to the green PL emission. In the model presented by Leonelli and Brebner, ${ }^{69}$ some of the electrons are promoted to the $\mathrm{CB}$ by absorption of photon from small polarons. The polarons interact with holes of the defect levels (crystal defect or impurity levels) in the crystal forming selftrapped excitons (STEs) that contribute to the visible PL emission [Fig. 10(c)]. The STE can also form in an ideal (nondefective) crystal when an excited electron and hole can lower their energy by creating a localized defect in the lattice; this is an example of spontaneous symmetry breaking. ${ }^{70}$

Our order-disordered model, in particular, the PWO-p model, is presented at last. The most important events happen before excitation. The structural order-disorder generates localized states and inhomogeneous charge distribution in the cell, thus allowing the trapping of electrons and holes. Those localized levels are energetically distributed, so that various energies are able to excite the trapped electrons. The radiative decay must occur through the same pathway, leading to a wide band emission.

\section{CONCLUSIONS}

The increase of structural ordering of the PWO thin films by annealing from 200 to $500{ }^{\circ} \mathrm{C}$ was identified by means of $\mathrm{XRD}$, absorbance spectra, and AFM measurements.

The PL emission in crystalline PWO was practically absent. For the sample containing the highest structural disorder, the intense PL emission is also not favored. The intense and broad PL emissions were evidenced in PWO thin films containing simultaneously order and disorder in the structure. The broad PL bands present green and red emissions. The experimental results also show that the red PL emission is associated with high structural disorder and the green PL emission is associated with smaller structural disorder degree in the PWO lattice. The most intense PL emission was favorable to PWO structure annealed at temperature just before to the crystallization temperature.

The theoretical calculations indicate that locally disordered $\mathrm{Pb}$ clusters are more favorable for the PL effect due to great local electronic holes induced by smaller distortions in the lattice, favoring electron transfers when submitted to photon excitation. The experimental and theoretical results indicate that green PL emission is related to locally disordered $\mathrm{Pb}$ atoms.

\section{ACKNOWLEDGMENTS}

The work was partially supported by the Brazilian agencies FAPESP/CEPID, CNPq, CAPES, and by the Fundación Bancaixa (Project No. P1-1B2005-20).

\footnotetext{
*Electronic address: marcos@liec.ufscar.br

${ }^{1}$ F. A. Kroger, Some Aspects of the Luminescence of Solids (Elsevier, Amsterdam, 1948).

${ }^{2}$ J. A. Groenink and G. Blasse, J. Solid State Chem. 32, 9 (1980).

${ }^{3}$ G. Blasse and B. C. Grabmaier, Luminescent Materials (SpringerVerlag, Berlin, 1994).
}

${ }^{4}$ P. Lecoq, I. Dafinei, E. Auffray, M. Schneegans, M. V. Korzhik, O. V. Missevitch, V. B. Pavlenko, A. A. Fedorov, A. N. Annenkov, V. L. Kostylev et al., Nucl. Instrum. Methods Phys. Res. A 365, 291 (1995).

${ }^{5}$ A. N. Belsky, V. V. Mikhailin, A. N. Vasilev, I. Dafinei, P. Lecoq, C. Pedrini, P. Chevallier, P. Dhez, and P. Martin, Chem. Phys. 
Lett. 243, 552 (1995).

${ }^{6}$ M. Nikl, K. Nitsch, K. Polak, E. Mihokova, I. Dafinei, E. Auffray, P. Lecoq, P. Reiche, R. Uecker, and G. P. Pazzi, Phys. Status Solidi B 195, 311 (1996).

${ }^{7}$ M. V. Korzhik, V. B. Pavlenko, T. N. Timoschenko, V. A. Katchanov, A. V. Singovskii, A. N. Annenkov, V. A. Ligun, I. M. Solskii, and J. P. Peigneux, Phys. Status Solidi A 154, 779 (1996).

${ }^{8}$ G. Tamulaitis, S. Buracas, V. P. Martinov, V. D. Ryzhikov, H. H. Gutbrod, and V. I. Manko, Phys. Status Solidi A 157, 187 (1996).

${ }^{9}$ M. Kobayashi, M. Ishii, K. Harada, Y. Usuki, H. Okuno, H. Shimizu, and T. Yazawa, Nucl. Instrum. Methods Phys. Res. A 373, 333 (1996)

${ }^{10}$ R. Y. Zhu, D. A. Ma, H. B. Newman, C. L. Woody, J. A. Kierstead, S. P. Stoll, and P. W. Levy, Nucl. Instrum. Methods Phys. Res. A 376, 319 (1996).

${ }^{11}$ V. Murk, M. Nikl, E. Mihokova, and K. Nitsch, J. Phys.: Condens. Matter 9, 249 (1997).

${ }^{12}$ D. Millers, S. Chernov, L. Grigorjeva, and V. Pankratov, Radiat. Meas. 29, 263 (1998)

${ }^{13}$ M. Nikl, P. Strakova, K. Nitsch, V. Petricek, V. Mucka, O. Jarolimek, J. Novak, and P. Fabeni, Chem. Phys. Lett. 291, 300 (1998).

${ }^{14}$ M. Martini, F. Meinardi, G. Spinolo, A. Vedda, M. Nikl, and Y. Usuki, Phys. Rev. B 60, 4653 (1999).

${ }^{15}$ O. Antonenko, O. Chukova, Y. Hizhnyi, S. Nedilko, and V. Scherbatskyi, Opt. Mater. (Amsterdam, Neth.) 28, 643 (2006).

${ }^{16}$ M. Kobayashi, M. Ishii, Y. Usuki, and H. Yahagi, Nucl. Instrum. Methods Phys. Res. A 333, 429 (1993).

${ }^{17}$ G. Blasse, Chem. Mater. 6, 1465 (1994).

${ }^{18}$ P. Lecoq, Nucl. Instrum. Methods Phys. Res. A 537, 15 (2005).

${ }^{19}$ V. G. Baryshevsky, M. V. Korzhik, V. I. Moroz, V. B. Pavlenko, A. S. Kobko, A. A. Fyodorov, V. A. Kachanov, V. L. Solovjanov, B. I. Zadneprovsky, V. A. Nefyodov et al., Nucl. Instrum. Methods Phys. Res. A 322, 231 (1992).

${ }^{20}$ B. G. Han, X. Q. Feng, G. Q. Hu, Y. X. Zhang, and Z. W. Yin, J. Appl. Phys. 86, 3571 (1999).

${ }^{21}$ M. Nikl, K. Nitsch, J. Hybler, J. Chval, and P. Reiche, Phys. Status Solidi B 196, K7 (1996).

${ }^{22}$ M. Nikl, J. Rosa, K. Nitsch, H. R. Asatryan, S. Baccaro, A. Cecilia, M. Montecchi, B. Borgia, I. Dafinei, M. Diemoz et al., Mater. Sci. Forum 239-242, 271 (1997).

${ }^{23}$ A. Annenkov, E. Auffray, M. Korzhik, P. Lecoq, and J. P. Peigneux, Phys. Status Solidi A 170, 47 (1998).

${ }^{24}$ V. N. Shevchuk and I. V. Kayun, Phys. Solid State 47, 632 (2005).

${ }^{25}$ T. Y. Liu, Q. R. Zhang, and S. L. Zhuang, J. Electron Spectrosc. Relat. Phenom. 142, 139 (2005).

${ }^{26}$ Q. R. Zhang, T. Y. Liu, J. Chen, and X. Q. Feng, Phys. Rev. B 68, 064101 (2003).

${ }^{27}$ M. Nikl, Phys. Status Solidi A 178, 595 (2000).

${ }^{28}$ M. Nikl, K. Nitsch, S. Baccaro, A. Cecilia, M. Montecchi, B. Borgia, I. Dafinei, M. Diemoz, M. Martini, E. Rosetta et al., J. Appl. Phys. 82, 5758 (1997).

${ }^{29}$ A. N. Annenkov, A. A. Fedorov, P. Galez, V. A. Kachanov, M. V. Korzhik, V. D. Ligun, J. M. Moreau, V. N. Nefedov, V. B. Pavlenko, J. P. Peigneux et al., Phys. Status Solidi A 156, 493 (1996).

${ }^{30}$ Z. M. Qi, C. S. Shi, D. F. Zhou, H. G. Tang, T. Liu, and T. D. Hu, Physica B 307, 45 (2001).
${ }^{31}$ C. Shi, Y. Wei, X. Yang, D. Zhou, C. Guo, J. Liao, and H. Tang, Chem. Phys. Lett. 328, 1 (2000).

${ }^{32}$ A. A. Annenkov, M. V. Korzhik, and P. Lecoq, Nucl. Instrum. Methods Phys. Res. A 490, 30 (2002).

${ }^{33}$ S. Baccaro, B. Borgia, A. Cecilia, I. Dafinei, M. Diemoz, P. Fabeni, M. Niki, M. Martini, M. Montecchi, G. Pazzi et al., Nucl. Phys. B 61, 66 (1998).

${ }^{34}$ E. V. Sokolenko, V. M. Zhukovskii, E. S. Buyanova, and Y. A. Krasnobaev, Inorg. Mater. 34, 499 (1998).

${ }^{35}$ B. M. Sinelnikov, E. V. Sokolenko, and V. Y. Zvekov, Inorg. Mater. 32, 999 (1996).

${ }^{36}$ Y. H. Chen, C. S. Shi, and G. Q. Hu, J. Appl. Phys. 87, 1503 (2000).

${ }^{37}$ Y. L. Huang, W. L. Zhu, and X. Q. Feng, J. Electron Spectrosc. Relat. Phenom. 133, 39 (2003).

${ }^{38}$ M. Kakihana, T. Okubo, M. Arima, Y. Nakamura, M. Yashima, and M. Yoshimura, J. Sol-Gel Sci. Technol. 12, 95 (1998).

${ }^{39}$ M. Kakihana and M. Yoshimura, Bull. Chem. Soc. Jpn. 72, 1427 (1999).

${ }^{40}$ F. M. Pontes, J. H. G. Rangel, E. R. Leite, E. Longo, J. A. Varela, E. B. Araujo, and J. A. Eiras, Thin Solid Films 366, 232 (2000).

${ }^{41}$ F. M. Pontes, E. Longo, J. H. Rangel, M. I. Bernardi, E. R. Leite, and J. A. Varela, Mater. Lett. 43, 249 (2000).

${ }^{42}$ V. R. Saunders, R. Dosevi, C. Roetti, R. Orlando, C. M. ZicovichWilson, N. M. Harrison, K. Doll, B. Civalleri, I. J. Bush, P. D'Arco et al., CRYSTAL2003 User's Manual (University of Torino, Torino, 2003).

${ }^{43}$ C. Lee, W. Yang, and R. G. Parr, Phys. Rev. B 37, 785 (1988).

${ }^{44}$ A. D. Becke, J. Chem. Phys. 98, 5648 (1993).

${ }^{45}$ C. H. Hu and D. P. Chong, Encyclopedia of Computational Chemistry (Wiley, Chichester, 1998).

${ }^{46} \mathrm{http}: / / \mathrm{www}$. crystal.unito.it

${ }^{47}$ V. L. Cabal, OPTIM User's Manual (Departamento de Quimica Fisica y Analitica, University of Oviedo, Oviedo, 1998).

${ }^{48}$ J. M. Moreau, P. Galez, J. P. Peigneux, and M. V. Korzhik, J. Alloys Compd. 238, 46 (1996).

${ }^{49}$ E. Gurmen, E. Daniels, and J. S. King, J. Chem. Phys. 55, 1093 (1971).

${ }^{50}$ A. Kokalj, J. Mol. Graphics Modell. 17, 176 (1999).

${ }^{51}$ M. Anicete-Santos, F. C. Picon, M. T. Escote, E. R. Leite, P. S. Pizani, J. A. Varela, and E. Longo, Appl. Phys. Lett. 88, 211913 (2006).

${ }^{52}$ E. Orhan, M. Anicete-Santos, M. A. M. A. Maurera, F. M. Pontes, C. O. Paiva-Santos, A. G. Souza, J. A. Varela, P. S. Pizani, and E. Longo, Chem. Phys. 312, 1 (2005).

${ }^{53}$ E. Orhan, M. Anicete-Santos, M. A. M. A. Maurera, F. M. Pontes, A. G. Souza, J. Andres, A. Beltran, J. A. Varela, P. S. Pizani, C. A. Taft et al., J. Solid State Chem. 178, 1284 (2005).

${ }^{54}$ A. T. de Figueiredo, S. de Lazaro, E. Longo, E. C. Paris, J. A. Varela, M. R. Joya, and P. S. Pizani, Chem. Mater. 18, 2904 (2006).

${ }^{55}$ E. Orhan, J. A. Varela, A. Zenatti, M. F. C. Gurgel, F. M. Pontes, E. R. Leite, E. Longo, P. S. Pizani, A. Beltran, and J. Andres, Phys. Rev. B 71, 085113 (2005).

${ }^{56}$ E. Longo, E. Orhan, F. M. Pontes, C. D. Pinheiro, E. R. Leite, J. A. Varela, P. S. Pizani, T. M. Boschi, F. Lanciotti, A. Beltran et al., Phys. Rev. B 69, 125115 (2004).

${ }^{57}$ E. Orhan, F. M. Pontes, E. R. Leite, P. S. Pizani, J. A. Varela, and E. Longo, ChemPhysChem 6, 1530 (2005).

${ }^{58}$ E. Orhan, F. M. Pontes, M. A. Santos, E. R. Leite, A. Beltran, J. 
Andres, T. M. Boschi, P. S. Pizani, A. Varela, C. A. Taft et al., J. Phys. Chem. B 108, 9221 (2004).

${ }^{59}$ M. Anicete-Santos, L. S. Cavalcante, E. Orhan, E. C. Paris, L. G. P. Simoes, M. R. Joya, I. L. V. Rosa, P. R. de Lucena, M. R. M. C. Santos, L. S. Santos-Junior et al., Chem. Phys. 316, 260 (2005)

${ }^{60}$ D. L. Wood and J. Tauc, Phys. Rev. B 5, 3144 (1972).

${ }^{61}$ C. J. Bradley and A. P. Cracknell, The Mathematical Theory of Symmetry in Solids (Clarendon, Oxford, 1972).

${ }^{62}$ Y. Zhang, N. A. W. Holzwarth, and R. T. Williams, Phys. Rev. B 57, 12738 (1998).

${ }^{63}$ Y. B. Abraham, N. A. W. Holzwarth, R. T. Williams, G. E. Matthews, and A. R. Tackett, Phys. Rev. B 64, 245109 (2001).

${ }^{64}$ M. S. Silva, M. Cilense, E. Orhan, M. S. Goes, M. A. C.
Machado, L. P. S. Santos, C. O. Paiva-Santos, E. Longo, J. A. Varela, M. E. Zaghete et al., J. Lumin. 111, 205 (2005).

${ }^{65}$ W. Vanloo, Phys. Status Solidi A 27, 565 (1975).

${ }^{66}$ F. Montoncello, M. C. Carotta, B. Cavicchi, M. Ferroni, A. Giberti, V. Guidi, C. Malagu, G. Martinelli, and F. Meinardi, J. Appl. Phys. 94, 1501 (2003).

${ }^{67}$ F. Kellendonk and G. Blasse, J. Chem. Phys. 75, 561 (1981).

${ }^{68}$ S. H. M. Poort, W. P. Blokpoel, and G. Blasse, Chem. Mater. 7, 1547 (1995).

${ }^{69}$ R. Leonelli and J. L. Brebner, Phys. Rev. B 33, 8649 (1986).

${ }^{70}$ S. Ismail-Beigi, Phys. Status Solidi C 10, 3365 (2006).

${ }^{71}$ JCPDS-International Center for Diffraction Data, Card No. 8-490 (unpublished). 